\title{
Research on the Dynamic Evolution of Residual Stress in Thermal Processing of Diesel Engine Blocks Based on FEM
}

\author{
ma zhengyu ${ }^{1}$ \\ ${ }^{1}$ Jiangsu University of Science and Technology
}

August 22, 2020

\begin{abstract}
The residual stress generated during the thermal processing process such as casting and heat treatment is one of the key reasons for the irreversible deformation of the diesel engine block. However, the previous research only conducted research and analysis unilaterally from the residual stress generated by casting or the effect of annealing heat treatment on the residual stress of castings, and the analysis results were quite different from the actual ones. Therefore, a comprehensive research method is proposed to consider the whole dynamic evolution process of castings from casting residual stress to heat treatment stress elimination. Through PROCAST numerical simulation of the casting process of diesel engine blocks, the simulation results of casting residual stress are introduced into the ABAQUS, and then the model of block casting with casting residual stress is simulated by annealing heat treatment. To realize the dynamic evolution of residual stress from casting to heat treatment.
\end{abstract}

\section{Hosted file}

Research on the Dynamic Evolution of Residual Stress in Thermal processing of Diesel Engine Blocks Base available at https://authorea.com/users/352986/articles/477032-research-on-the-dynamicevolution-of-residual-stress-in-thermal-processing-of-diesel-engine-blocks-based-on-fem 